\title{
Effects of music on tonic heat pain in depression-a preliminary investigation
}

Stefan Gebhardt ${ }^{1 *}$, Martin T. Huber ${ }^{1,2}$ and Richard von Georgi ${ }^{3,4}$

*Correspondence: Stefan.Gebhardt@uni-marburg.de

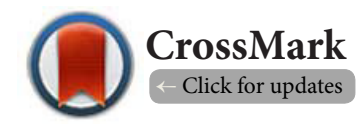

'Department of Psychiatry and Psychotherapy, University of Marburg, Germany.

${ }^{2}$ Department of Psychiatry, Psychotherapy and Psychosomatics, Hospital of Stade, Germany.

${ }^{3}$ Department of Music science and Music education, University of Giessen, Germany.

${ }^{4}$ International Psychoanalytic University Berlin, Berlin, Germany.

\begin{abstract}
Background: An altered pain perception is a common clinical feature in patients with depressive disorders. However, the question of how listening to music influences pain perception in subjects with depression has not yet been studied.

Aims: The aim of the study was to test the hypothesis that music reduces the severity of pain in patients with depressive disorders. For the investigation the tonic heat pain model was used as it is suitable to simulate chronic pain.

Methods: Repeated measurement design on $n=20$ patients with a depressive disorder (mean age $49 \pm 14$ years). Subjective pain ratings were assessed two times without and once with music, each trial lasted 5 minutes with measurements taken every minute.

Results: Under the influence of music the patients showed significantly reduced pain ratings compared to the trial without music $(\mathrm{p}<0.05)$.

Conclusions: The use of music appears to be effective on pain symptomatology in patients suffering from depressive disorders. Further studies are warranted to examine the use of music within a therapeutic context.
\end{abstract}

Keywords: Music, pain, depression, tonic heat, therapy

\section{Introduction}

An altered pain perception is a common phenomenon in patients with depressive disorders and is prognostically unfavourable. $5-13 \%$ of the general population suffer from a depressive disorder, a third hereof can be classified as chronic; $40-75 \%$ of patients with depressive disorders report pain symptoms (see review: [1]). In experimental investigations patients with depressive disorders showed elevated pain thresholds, although they complained of an increased pain symptomatology at the same time. The underlying mechanisms are not yet fully understood, but an impairment of the descending pain-inhibitory system in depressive disorders has been hypothesized [2].

The contribution of the positive emotional property of music to music-induced analgesia is well known [3], and the analgesic effect of music has been proven many times, e.g., in postoperative pain [4] or in chronic pain [5-7]. To our knowledge, however, no reports exist on the influence of music on pain perception in patients with depressive disorders. Therefore the aim of the present study was to investigate whether listening to music results in a reduction of the severity of pain in this population. For the current investigation the tonic heat pain model has been used which enables the generation of stable pain states and which is considered as a model for simulating chronic pain. Hereby, tonic heat pain gets more closely to clinical pain than the phasic heat pain stimulation, which has predominantly been used in previous studies.

\section{Materials and methods \\ Study sample}

Twenty patients ( 11 males, mean age $49 \pm 14$ years), admitted at the Department of Psychiatry and Psychotherapy of the Philipps-University of Marburg/Germany with a manifest 
depressive disorder according to ICD-10, were included in the study. Inclusion criteria were an unipolar depressive disorder, no concomitant psychotic disorder or personality disorder, no other severe acute or chronic medical or neurological disorder or pregnancy. Patients gave written informed consent; the study was approved by the Ethics Committee of the University of Marburg.

At the time of the experiment the mean score of the Hamilton rating scale for depression (HAMD) was $24.3 \pm 5.8$ representing a moderate depressive symptomatology. Of the 20 participants, 12 experienced recurrent depressive episodes. Mean time since onset of the depressive disorder (first episode) was 5.8 \pm 8.8 years. Baseline pain, assessed on a visual analog scale ranging from 0 to 10 , was rated in average with $2.8 \pm 2.5$. Whereas 7 patients reported not suffering from any pain before the beginning of the experiment, the remaining 13 patients rated $4.3 \pm 1.6$ on the visual analog scale. Mean global assessment of functioning (GAF) score was 51.2 \pm 6.9 .

7 patients received selective serotonin and norephinephrine reuptake inhibitors (SSNRI), 5 patients selective serotonin reuptake inhibitors (SSRI), 1 patient a selective dopamine and norepinephrine reuptake inhibitor. Mirtazapine was administered in 1 patient as monotherapy and in 4 patients as co-medication. Further 2 patients had tricyclic antidepressants as co-medication. 6 patients were not treated with antidepressant medication at the time of the examination (of these, two patients have received mirtazapine and one patient a SSNRI at least 24 hours before the experiment). Low doses of atypical antipsychotics received 7 patients, 1 patient lorazepam. Six patients were smokers, mean BMI was $27.0 \pm 5.5 \mathrm{~kg} / \mathrm{m}^{2}$ (slightly overweight). In respect of the 5 premenopausal women, all of them were at the first half of menstrual cycle, two of them received contraceptive agents. Ten patients had completed a secondary school education, 7 had a secondary school certificate, and 3 a general qualification for university entrance. 14 patients had a finished job education, 3 were academics, 2 patients had never had a job before and 1 patient was a student.

\section{Assessment}

After determination of the individual pain thresholds patients were familiarized with the pain ratings and questionnaires. This was followed by a period of $10 \mathrm{~min}$ of adaptation to the experimental settings by carrying out test runs without listening to music. The session itself consisted of six blocks with the following stimulation conditions (randomly assigned): 1 . tonic non-painful heat, 2. non-painful warmth, 3. tonic painful heat, 4. tonic non-painful heat, 5. tonic painful heat, 6 . non-painful warmth, with pauses of at least 5 min between each block. After these six blocks, an additional painful heat stimulation block with music was performed. Heat pain was applied by means of a femoral thermoelectrode with an undulation of the heat stimulus between $1{ }^{\circ} \mathrm{C}$ above and $0.3^{\circ} \mathrm{C}$ below the individual pain threshold with a constant frequency of $30 \mathrm{pulses} / \mathrm{min}$. Each minute patients were asked to rate the actual perceived pain intensity on a 0-100-points-scale, while they had no information of the objective level of heat.

For the evaluation of the current issue only the blocks with painful heat stimulation over 5 min were evaluated, that is block 3, 5 (both without music) and the final trial with music. Subjective pain ratings were assessed two times without music and finally once with music, each of the 3 trials lasted 5 minutes with measurements taken every minute. For the music trial patients listened by earphones to "Due" by Laura Pausini, a piece of popular music with a positive stimulating character. The patients were asked to listen attentively to the music.

\section{Statistics}

Differences of the subjective pain ratings were analyzed by $3 \times 5$ analysis of variance (ANOVA) for repeated within measures (trials, measures). T-tests for dependent measures were used as post-hoc test. Level of significance was set to $a \leq 0.05$.

\section{Results}

The analysis resulted in no significant main effect for the difference between the three trials ( $p=0.122$ ), but a strong effect could be observed when analyzing the measurements of the time points $1^{\text {st }}$ to $5^{\text {th }}$ minute: Over the 5 time points the pain rating increased significantly $(p=0.002)$. Further, a significant interaction effect between trials and the point of measure (time) could be identified $(p=0.045)$. Hereby, the musical condition led to significantly lower pain ratings at the endpoint; (t-test: $p=0.009$ and $p=0.031$ ) (see Figure 1).

\section{Discussion}

This study explored the effect of listening to music on pain perception in adults with depressive disorders. Listening to music significantly reduced the perceived pain intensity. To our knowledge the current study is the first one, which deals with the influence of hearing music on tonic pain perception in patients with depressive disorders.

A neurobiologically based connection between the both entities "depression" and "pain" is well known [8]. For example, anatomical regions as well as neurochemical factors involved in affect regulation play also an important role in the pain system (e.g., anterior cingulate cortex, amygdala, hippocampus; serotonin/norepinephrine, neurotrophic factors) [8]. Simultaneously it is known, that music directly influences cortical and basic emotional systems [9]. Thus, the modulation of emotional activity (see [10]) could also influence pain perception.

The current study suggests an obvious pain reduction under the use of music in patients with depressive disorders, while the analgesic and antidepressive effect of music in chronic pain patients has already been shown $[6,11]$. However, the mechanism remains unclear. It is assumed that music affects directly subcortical regions, regulating both pain and 


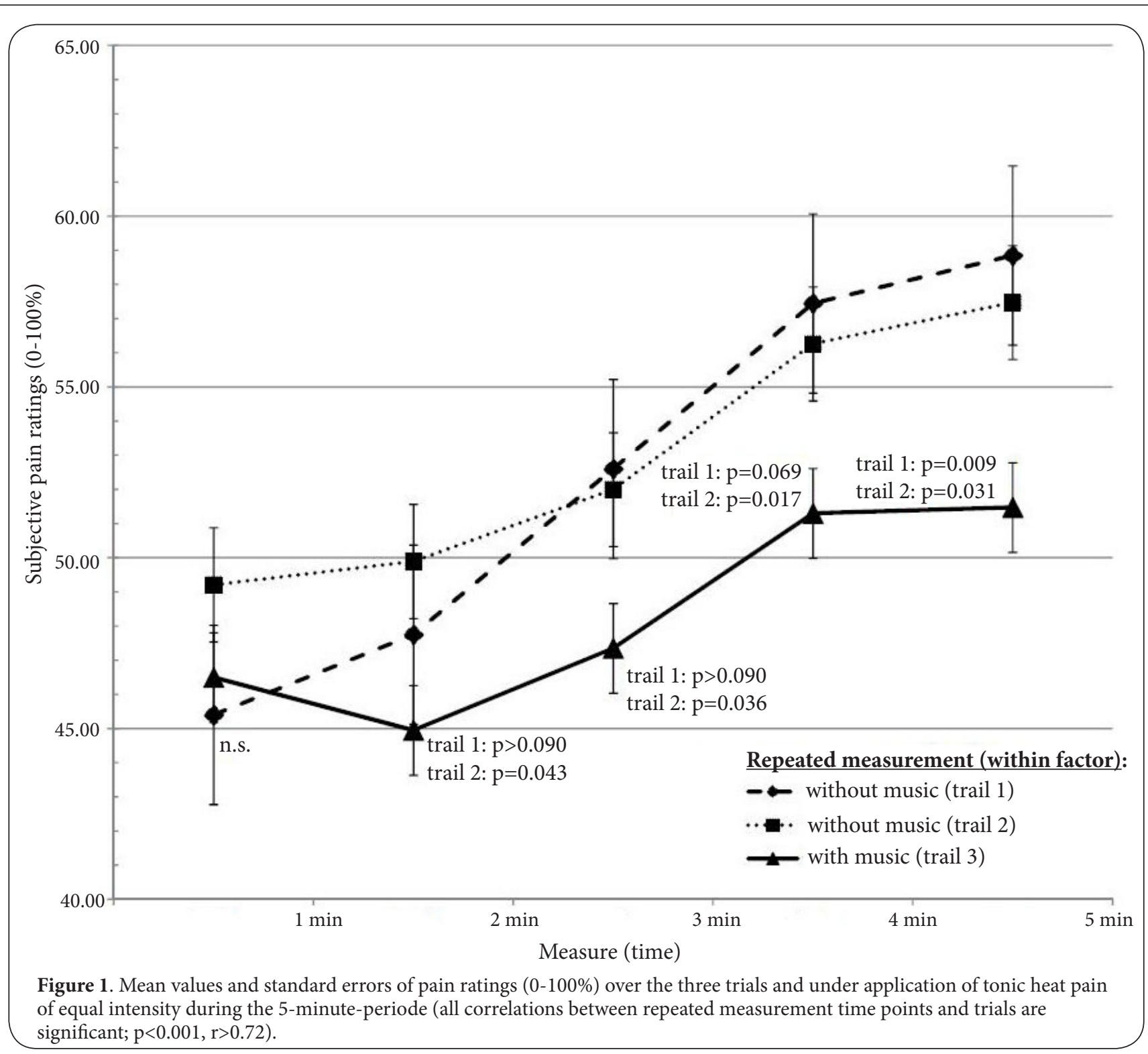

emotions [8,9], and has also a direct physiologic effect through the autonomic nervous system [12]. But also more indirect effects of music on pain can be discussed, e.g., by primarily modulating mood, the arousal system or even the cognitive (cortical) control on subcortical regions. A complex interplay of these factors with individual features appears to be likely. So far no studies exist, which have investigated the role of the functional use of music in relation to specific characteristics such as personality or anxiety in patients suffering from mental disorders. One study indicates that individuals with affective disorders use music predominantly in order to relax [13]. Whether individuals with depression use the hearing of music with the intention of reducing symptoms cannot be deduced from this study. Another study could show a reduction of both depression and chronic pain without being able to explain the mechanisms involved in the effects of listening to music on pain perception [7]. Of course it cannot totally be ruled out that music merely works as a distraction stimulus resulting in an inhibition of incoming pain signals in the spinal cord [14]. Nevertheless, in the experiment the patients had been asked to listen actively to the music. Furthermore, we refer to music as a strong, complex emotional stimulus, whose effects on psychovegetative, emotional and cognitive functions have often been described e.g., [3,12].

The music used, which showed this pain-relieving effect, was a positively stimulating one. Interestingly, the research group in Jena, Germany, found reduced heat pain thresholds after an music-induced sad-mood in healthy subjects and showed a functional relationship to the fronto-thalamic network using a MRI-scanner [15]. However, in a recent Chinese study [16] both, happy and sad music of equal valence (pleasantness) resulted in significantly lower pain ratings. The 
authors suggested, that the valence of music (pleasant versus unpleasant) rather than the mood, modulates the hypoalgesic effect of music. Furthermore, no significant differences in the influence on pain or depression could be detected in chronic pain patients ( $\mathrm{n}=18 \mathrm{vs}$. $\mathrm{N}=22 ;(6))$ between subject-preferred and researcher-provided music.

Interestingly, in the current study the comparison between the second trial and the music-trial shows earlier significant results than the comparison between the first trial and the music-trial (see Figure 1). One could speculate that the more patients have suffered from pain, the stronger the effect of music would be.

The fact, that no significant main effect could be detected among the three trials, but a strong effect of the points of time of the measurements as well as a significant interaction effect between the trials and the points of the measurements could be seen, leads to the assumption that pain intensity might only be influenced by music in the course of the persistent pain. Certainly, the complexity of other factors influences the effectiveness of music on pain. A study on patients with post-surgical pain showed in a first experiment that listening to music resulted in significantly less anxiety, but in no reduction of pain. In a second experiment, however, no effect of music on either anxiety or pain could be observed [17]. The first experiment was performed after a minor surgery on the foot and the patients were of mixed gender, the second experiment took place after an abdominal hysterectomy, which is a more extensive procedure that involves more psychological distress and involves only female patients.

The strength of the study is the empirical approach by using the tonic heat pain model as a model for persistent (chronic) pain and the direct comparison of treatments without and with music. The study is limited by real-world conditions (e.g., different pharmacotherapy), a small sample size and a missing control group of healthy subjects.

Transferring the results into clinical praxis, the data presented provide a first preliminary empirical approach to the question of whether and how listening to music influences depressed mood and comorbid pain symptomatology. The experimental setting was rather non-therapeutic: for example, investigator and patient had no therapeutic relationship before or after the trial so that psychosocial effects were mainly neglected. Both, a direct emotion modulating effect of music as well as an intrapersonal dynamic one could be relevant. For example, the self-orientated focus in depression [18] might be altered by turning the focus to music with a positive emotional valence. This suggests a relation to the theory of mindfulness. As well, there is a clear aspect of euthymic treatment [19]. Nevertheless, the strong interpersonal component of music therapy by the therapeutic relationship or inter-group relations, which has not been examined in the present study, should provide an additional long-term treatment effect, as for example described by Haffa-Schmidt [20] for music therapy in patients with oncologic diseases. It goes without saying that much more complex psychotherapeutic treatment effects of music therapy such as improving the self-image or activation of resources, approaching to and coping with inner conflicts, and even bodily aspects such as developing activity may play a strong role for the long-term treatment process.

However, in the present study we could detect an isolated effect of music on pain by probably short-term emerging emotion modulation, which opens new therapeutic perspectives, e.g., towards the learning of strategies on the use of music in everyday life. This would implicate a psycho-educative role of music therapeutics, psychologists or physicians in the sense of supporting self-help. Nowadays music has such a strong impact on daily life (e.g., listening to music in public transportation) and is available like food at any time and any place, so when considering its emotion modulating effects a mindful use is crucial for individuals with a sensitivity for an emotional destabilization. In particular, depressive patients might expose themselves to music in a dysfunctional manner, which could increase their depressive symptomatology. On the other hand, if patients were instructed how to use music constructively, they could have the chance to reduce their negative affects by including bodily impairments such as pain symptoms. First approaches could show a prolonged effect of music therapy on the use of music in everyday life in psychiatric patients [21].

There is already substantial knowledge of active and receptive music therapy for both depressive and pain disorders which can be transferred into a psycho-educative treatment approach. Moreover, there are already treatment modalities and evaluated standards, which are used in somatic medicine, e.g., for post-surgical pain. However, detailed strategies how to use music constructively have still to be evaluated and established. One way could be the therapeutic strategy of "acting opposite" according to the dialectic behavioural therapy [22]; e.g., when a patient feels anxious, she/he can change the music with an anxious-frustrating character to music with a neutral or even curious nature. Nevertheless the initial pickup of the anxious emotion by a respective piece of music is certainly useful in the sense of an authentic experience of current emotional states. Depressive patients might even have a lack of strategies in reducing negative activation [13], so that some patients have to be instructed to use negative emotions, e.g., to let aggression happen. Further studies on such strategies are necessary. Especially an approach that connects personality dimensions with the individual use of music should be explored [23].

It can be assumed that the approach towards a direct emotion modulating concept should not only have short-term effects, but also long-term ones by improving the daily emotion modulating strategies and therefore the neurobiological system by influencing neurotramitter systems, neurotrophic factors and therefore even neurogenesis positively. The shift of focus from pain towards the use of music as a positive emotion modulating strategy in everyday life provides also the 
Gebhardt et al. Pain and Relief Reports 2014,

opportunity to an improving life quality despite of chronic pain.

\section{Conclusions}

The use of music within a therapeutic context appears to be effective on pain symptomatology in patients suffering from depressive disorders. In the light of the worldwide high prevalence of depressive disorders and chronic pain symptomatology with a frequently not sufficient response to antidepressant drug therapy, new non-psychopharmacological treatment methods are necessary. In this context, music could reach more significance by directly influencing neurobiological systems and the related depressive symptomatology, especially considering the low costs and its ubiquitous existence. A well-aimed administration in psychiatric clinics should be discussed. Further studies are necessary that lead to a better insight into the mechanisms by which music influences pain in depressive disorders.

\section{List of abbreviations}

GAF: Global assessment of functioning

HAMD: Hamilton rating scale for depression

ICD: International classification of disorders

\section{Competing interests}

The authors declare that they have no competing interests.

Authors' contributions

\begin{tabular}{|l|c|c|c|}
\hline Authors' contributions & SG & MTH & RVG \\
\hline Research concept and design & $\checkmark$ & $\checkmark$ & $\checkmark$ \\
\hline Collection and/or assembly of data & $\checkmark$ & $\checkmark$ & -- \\
\hline Data analysis and interpretation & $\checkmark$ & -- & $\checkmark$ \\
\hline Writing the article & $\checkmark$ & -- & -- \\
\hline Critical revision of the article & $\checkmark$ & $\checkmark$ & $\checkmark$ \\
\hline Final approval of article & $\checkmark$ & $\checkmark$ & $\checkmark$ \\
\hline Statistical analysis & $\checkmark$ & -- & $\checkmark$ \\
\hline
\end{tabular}

Acknowledgement and funding

The authors would like to thank Prof. Stefan Lautenbacher,

Bamberg/Germany, for providing the environment

for the study, and Prof. Jürgen-Christian Krieg for

having supported this study on the patients of the

Department of Psychiatry and Psychotherapy, University

of Marburg/Germany and for his helpful, critical

comments. There was no special funding of the study.

Publication history

Editors: Jin Sung Choi, The Catholic University of Korea, South Korea. Ainiu Ma, Shanghai Jiao Tong University, China.

Received: 26-Aug-2014 Final Revised: 25-Sep-2014

Accepted: 31-Oct-2014 Published: 07-Nov-2014

\section{References}

1. Gebhardt $\mathrm{S}$ and Lautenbacher S. Pain in depressive disorders. In: Marchand S, Saravane D, Gaumond I (Eds.), Mental Health and Pain. Somatic and Psychiatric Components of Pain in Mental Health. Springer Paris, Heidelberg, New York, Dordrecht, London. 2014; 99-117. I Book

2. Lautenbacher $\mathrm{S}$ and Krieg JC. Pain perception in psychiatric disorders: a review of the literature. J Psychiatr Res. 1994; 28:109-22. | Article | PubMed
3. Roy M, Peretz I and Rainville P. Emotional valence contributes to musicinduced analgesia. Pain. 2008; 134:140-7. | Article I PubMed

4. Engwall $M$ and Duppils GS. Music as a nursing intervention for postoperative pain: a systematic review. J Perianesth Nurs. 2009; 24:370-83. | Article | PubMed Abstract | PubMed Full Text

5. McCaffrey R and Freeman E. Effect of music on chronic osteoarthritis pain in older people. J Adv Nurs. 2003; 44:517-24. | Article | PubMed

6. Siedliecki SL and Good M. Effect of music on power, pain, depression and disability. J Adv Nurs. 2006; 54:553-62. | Article | PubMed

7. Guetin S, Ginies P, Siou DK, Picot MC, Pommie C, Guldner E, Gosp AM, Ostyn K, Coudeyre $E$ and Touchon J. The effects of music intervention in the management of chronic pain: a single-blind, randomized, controlled trial. Clin J Pain. 2012; 28:329-37. | Article | PubMed

8. Robinson MJ, Edwards SE, Iyengar S, Bymaster F, Clark M and Katon W. Depression and pain. Front Biosci (Landmark Ed). 2009; 14:5031-51. | Article I PubMed

9. Panksepp J and Bernatzky G. Emotional sounds and the brain: the neuro-affective foundations of musical appreciation. Behav Processes. 2002; 60:133-155. | Article | PubMed

10. von Georgi R, Grant P, von Georgi S and Gebhardt S. Personality, emotion and the use of music in everyday live: Measurement, theory and neurophysiological aspects of a missing link. Lübeck, Marburg: Der Andere Verlag. 2006.

11. Cepeda MS, Carr DB, Lau J and Alvarez H. Music for pain relief. Cochrane Database Syst Rev. 2006; CD004843. I Article I PubMed

12. Lemmer B. The rhythm of the heart - the tempus of music - Mozart, Ligeti and the Rat. In: Haas R \& Brandes V, (Eds), Music that works. Wien, New York: Springer. 2009; 167-178. I Book

13. Gebhardt S, Kunkel M and von Georgi R. Emotion modulation in psychiatric patients through music. Music Percept. 2014; 31:485-493. I Article

14. Sprenger C, Eippert F, Finsterbusch J, Bingel U, Rose M and Buchel C. Attention modulates spinal cord responses to pain. Curr Biol. 2012 22:1019-22. | Article | PubMed

15. Wagner G, Koschke M, Leuf T, Schlosser R and Bar KJ. Reduced heat pain thresholds after sad-mood induction are associated with changes in thalamic activity. Neuropsychologia. 2009; 47:980-7. | Article | PubMed

16. Zhao $\mathrm{H}$ and Chen AC. Both happy and sad melodies modulate tonic human heat pain. J Pain. 2009; 10:953-60. | Article | PubMed

17. MacDonald RAR, Mitchell LA, Dillon T, Serpell MG, Davies JB and Ashley $E A$. An empirical investigation of the anxiolytic and pain reducing effects of music. Psychol Music. 2003; 31:187-203.

18. Grimm S, Ernst J, Boesiger P, Schuepbach D, Boeker H and Northoff G. Reduced negative BOLD responses in the default-mode network and increased self-focus in depression. World J Biol Psychiatry. 2011; 12:62737. | Article | PubMed

19. Lutz R. [The therapeutic concept of euthymic treatment. The little school of pleasure]. MMW Fortschr Med. 2005; 147:41-3. I PubMed

20. Haffa-Schmidt U. Musiktherapie mit onkologischen Patienten. In: Nöcker-Ribaupierre M (Ed.), Musiktherapie und Schmerz. Wiesbaden: Reichert Verlag. 2008; 61-72. I Book

21. Silina A, von Georgi R, Gebhardt S and Weber B. Indirekte Wirkung der Musiktherapie: Transfereffekte auf die Verwendung von Musik im Alltag bei Personen mit psychischen Erkrankungen. Jahrestagung der Deutschen Gesellschaft für Musikpsychologie (DGM), Bremen. 2012.

22. Bohus M, Wolf M, Alf R, Gunia H and Jacob G. Interaktives Skillstraining für Borderline-Patienten im Set: Manual zur CD-ROM für die therapeutische Arbeit. Stuttgart: Schattauer. 2009. | Book

23. von Georgi R. Anwendung von Musik im Alltag. Theorie und Validierungsstudien zum IAAM. Marburg: Tectum Verlag. 2013. | Book

\section{Citation:}

Gebhardt S, Huber MT and von Georgi R. Effects of music on tonic heat pain in depression-a preliminary investigation. Pain Relief Rep. 2014; 1:1. http://dx.doi.org/10.7243/2057-3219-1-1 